\title{
Portraits of Educators' Language Practices Regarding Chinese Children's English Learning in Australian Long Day Care Centres
}

\author{
Jiangbo Hu \\ Department of Educational Studies, Macquarie University, Australia
}

\begin{abstract}
This paper reports five Australian educators' language practices relating to Chinese children's English learning in long day care centres. Portraiture methodology is employed in this study to present the investigation by embracing the views of the participants who negotiate their experiences with a desire of showing goodness of their practices. The five portraits of the educators were analyzed with Cummins' [2] framework for supporting English language learners' (ELL) language development with different language activities that are categorized with the dimensions of contextual support and cognitively demanding. The portraits, on one hand, reveal the goodness of the educators' practices that involve a variety of strategies supporting ELLs effectively, and some examples offered by the educators may be inspiring for other educators. However, on the other hand, the portraits demonstrate the challenges experienced by some educators whose practices draw heavily on body language that is highly context-embedded and lowly cognitive-demanding. They suggest some opportunities for enhancing educators' knowledge about different language strategies, especially highly context-embedded and highly cognitivedemanding language activities in practice. The implications from the study inform the avenue of future educator training programs in the field of education of ELLs.
\end{abstract}

\section{Introduction}

Lindy: "Lucas, can you please stand up and tell us what you are going to find in the basket?” (Lindy said to Lucas, a 5-year-old Chinese boy who was sitting in the group, joining in a game called "Shopping basket". Lucas stood up and held the shopping basket passed by a boy sitting next to him. He looked at Lindy.)

Lindy: "I went to the shop"

Lucas: "I went to the shop"

Lindy: "And I bought..."

Lucas: "And I bought..." (He took a book out of the basket)

Lindy: "What is that?"

Lucas: "Book"

Lindy: "A book, yes. Pass the basket to Cedar.”
This dialogue occurred in a group language game that Lindy created for children to practice describing an event in complete sentences. She put different items in the basket and asked children to take an item out one by one while using the sentence "I went to the shop and I bought a...” to label the items. Five items were placed in the basket. Children took turns to play the game with five at a time in a group. In each group, the first child should say the item he/she picked up, and the second child should say the items picked up by himself/herself as well as by the first child, for example "I went to the shop and I bought a ring and a book." The third, fourth and fifth children were then required to add the items to their sentences. The fifth child had to say the longest sentence by labeling all the five items. Lindy ensured that the game ran smoothly by guiding the children where necessary. All children showed interest by actively joining in the game and participated cooperatively. Lucas was guided by Lindy to sit in the second group. This provided him with an opportunity to watch the first group's performance before having his turn. He was in a position to be the first member in his group who only needed to say one item. He spoke the sentence with Lindy's modeling and encouragement. He also watched and listened attentively to the other children throughout the game.

Though this game was organized for all children, Lucas's additional language needs were carefully addressed by Lindy. Lindy placed Lucas in a position that made his task easier. She also used the strategy of modeling to guide him speak the sentence. In this activity, Lucas was provided with opportunities to hear and mimic comprehensible English in a context supported by props. According to Shin [13], this is an effective language activity for English language learners to use English with understanding of meanings.

The actions that Lindy had taken for Lucas in the game is just one of the examples to show how English background educators try to help English language learners (ELLs) develop English skills and include them in group activities in their long day care. Educating ELLs can be a challenging task. Educators need to combine sound knowledge and consideration of these children's particular needs in practice, as shown in the above example. Common behaviors among ELLs such as being silent, having 
difficulty in expressing ideas in English and following instructions may bring challenges to interactions and educational activities [12], [14]. This challenge seems to be pertinent, given the rapidly growing number of ELLs due to high level of immigration to Australia [1].

Research about the education of ELLs suggests a number of effective strategies for educators to support these children in the process of acquiring a second language and adapting to new environments. First, highlighting ELLs' culture, language and home experiences. ELLs show more motivation in learning new skills in an environment where their language and culture are valued [2]. They will be more engaged and generate more responses to topics connected with their cultures or the things they are familiar with. Chinese children may show more interest and understanding in topics relating to Chinese culture (e.g. Moon Festival). Second, using appropriate pedagogical strategies to facilitate ELLs' understanding of English in different contexts. For preschool-aged ELLs, providing opportunities for exposure to comprehensible English is necessary [13]. Educators can make their language more meaningful using strategies such as exaggerating body language and facial expression, speaking clearly and slowly, using pictures or props, or involving multi-media presentations [6]. Third, using scaffolding to foster reading skills and vocabulary learning. Pre-teaching of some key words enables ELLs to better understand the whole text [3]. Repetition of the same words in routines or regular learning events helps ELLs learn the words effectively [11]. Fourth, for young ELLs, poetry and songs are also great venues to enhance their phonological awareness [11].

Research in language education for ELLs mainly focuses on how to apply effective approaches to maximize children's language learning in educational environments. Many studies were undertaken in an environment where bilingual staff were available, or targeted interventions were being implemented. These studies sought to find ideal practices that educators should apply to support ELLs. However, little literature is available on educators' language practices with ELLs in regular settings. What language practices are evident in educators' interactions with these children? How do educators apply their knowledge of language education with ELLs? Knowledge in this area is limited. This study is designed to investigate Australian monolingual English early childhood educators' efforts in enhancing Chinese children's English skills in daily practices. The above two questions formed the central focus of this study. The reason for the focus on Chinese children is because first the number of Chinese children is increasing rapidly in Australian educational settings and Chinese constitutes one of the biggest ethnic groups in Australia [10]. Second, many Chinese children have little English language skills before entering an educational setting due to the dominant exposure to their home language in their families [7]. These children may experience difficulties in understanding and using English in early childhood settings and need substantial support from educators.

In the following sections, I first discuss the theoretical framework of language activities that support language development of ELLs. Then I introduce the participants and portraiture as a research methodology followed by five individual portraits. Finally, I discuss some issues revealed by the portraits that have implications for the language education of ELLs in long day care.

\section{Theoretical framework of language activities and second language development}

The process of achieving English language proficiency for ELLs is complex. According to Cummins [2], language proficiency refers to both casual language in social situations and academic language in educational environments. Casual language in social situations is often informal and occurs in environments where many language cues lie behind the actual words, such as an instruction with hand gestures. An understanding of intended meaning can be more easily gained by the combination of spoken words and cues. Cummins labels this type of language as context-embedded and cognitively undemanding. On the contrary, academic language is often context-reduced. It requires cognitive skills such as analysis and logical thinking in the interactions, for example a description of an abstract concept of a social phenomenon. In general, the process of language development of ELLs moves from contextembedded and cognitively undemanding casual language to context-reduced and cognitivedemanding academic language. ELLs may need five to ten years to achieve proficiency in academic language [2]. This might be challenging for some educators, particularly those working with ELLs who use fluent English in daily social conversation. These children seem to have achieved as high a proficiency in English as native English speaking children in casual communication. However, they may still need support in the development of formal academic language which is not immediately obvious to educators.

Cummins [2] used the following figure to describe the range of contextual support and degree of cognitive involvement in language activities that support the process of ELLs' English language development: 


\begin{tabular}{cc|cc} 
& \multicolumn{3}{c}{ Cognitively undemanding } \\
& \begin{tabular}{c|c} 
A \\
Context embedded
\end{tabular} & C & Context reduced \\
\cline { 2 - 3 } & B & D & \\
& & \\
& Cognitively demanding
\end{tabular}

Figure 1. Cummins' Framework of different types of language activities

Quadrant A represents highly context-based and less cognitively demanding language activities, such as daily conversations in routines and playground language. Quadrant D represents academic language, requiring a high level of cognitive demand with little environmental or interpersonal cues. Language development generally moves from quadrant A to quadrant D. Quadrant B is critical in this process. It refers to language activities involving cognitive demand provided with contextual support or scaffolded intervention. Most effective strategies suggested by research about education of ELLs are situated here. Quadrant B functions as a bridge between quadrants A and D. Quadrant C represents context-reduced and cognitively undemanding activities. Activities within this quadrant are occasionally used in the reinforcement or practice of particular aspects of language such as asking children to trace letters repeatedly.

Classroom language activities can be generally categorised into these four types. The type is determined not only by the language activity itself, but also by children's previous experiences and their language skills. For example, an educator reading the story of Snow White to children; this could be a B type activity for children who know the story well, but their English skills are at the level of only understanding key words and simple sentences drawn from the story. However, the same activity could be a D type activity if the children have never heard about Snow White.

To young ELLs, A and B types of activities are important for their language development because context-embedded communications are more comprehensible and negotiable [2]. The C and D types of activities are context-reduced, which are less comprehensible to preschool-aged children.

Cummins' framework is not limited to the discussion of the nature of different type of language activities, he emphasised the social factors that significantly shape the language activities in educational settings. He points out that the relations of social power between dominant and subordinate groups outside educational settings influence educators' language attitudes and practices, and educators play a critical role in negotiating their practices within frameworks of social power relations. For example, in the 1970s, immigrants were encouraged to abandon their home language and shift to English for assimilation. This factor could be reflected in educational settings. Educators could either strengthen the power by forbidding ELLs to speak their home language, or reduce the influence of the power by supporting home language based on their understanding of education of ELLs.

\section{Methodology}

This paper is drawn from a larger, multi-case study. Case study provides a broad underpinning for the current paper. While a case study approach allows for deep investigation of each case and crosscase comparisons, portraiture methodology is used to emphasize the characteristics of educators' language practices and the rich contexts in which they occur. This method enables me to focus on the goodness of the practices through interaction with the educators who negotiate the experiences [8]. It also allows me to embrace my views and experiences in the process of data collection and analysis [8]. According to Merriam, the combination of cross-case analysis and portraiture is advantageous in gaining both width and depth of an investigation of social phenomena [9].

\subsection{Portraiture as a research method}

Portraiture was first developed by LawrenceLightfoot in 1983 [5]. It is a research method blending art and science. Artistic expression and traditional qualitative inquiry work harmoniously in a portraiture study [8]. A portrait is more than a reflection of facts in a mirror. While accurately capturing main factual characteristics, it reveals truths in an artistic way through the understanding and experiences of the painter (researcher) as well as through the interactions between the painter and the painted (participants).

Portraiture highlights the importance of context which is similar to case study and anthropology. According to Lawrence-Lightfoot and Hoffmann Davis, rooting in a rich context is a central element of presentation of a study because context conveys the constraints and opportunities in the expression of participants.

While emphasizing the context of participants, the researcher's position is highly valued in portraiture research. The researcher's voice is woven into the portraits on purpose. LawrenceLightfoot and Hoffmann Davis [8] argue that interweaving the researcher's personal views is not to distract readers; instead, it helps readers to gain a deeper understanding of the research subject through researcher's views, and also have an awareness about the lens through which the issue is investigated. This is different from research that tries to maintain researcher objectivity by avoiding personal factors that influence description of the 
subject. However, in many situations, researchers are attracted to a topic due to their interests and backgrounds. Portraiture allows researchers' views and experiences to be embedded in the study. Portraiture recognizes the fact that the physical presence of a researcher unavoidably changes a research environment. The interaction with participants, the researcher's prior experiences and assumptions shape the setting in a subtle way. A first-person account is used in portraiture to reflect these attributes in the description.

As a Chinese immigrant and an early childhood educator, I have first-hand experience of learning English as a second language and I have worked with ELLs in a preschool in Sydney, which gives me a privileged insider's perspective. In the process of developing English skills, I met a lot of challenges similar to other ELLs, such as losing confidence in interacting with other people and having difficulties expressing ideas properly. I struggled to survive in a world that was very difficult for me to understand and adapt to. I have strong empathy with young ELLs who are facing the same challenges. Even though young children may find their own ways to adapt to the new environments and learn the new language sooner or later, I found that educators could help facilitate this process by intervening appropriately, as research has suggested. My experiences, especially empathy to ELLs and sensitivity to supportive interactions between educators and ELLs, influenced the process of data collection and analysis and the development of the portraits. For example, I was impressed by the educators' expression of caring for ELLs' socioemotional feelings in language learning, which is reflected in the educators' portraits.

Another unique characteristic of portraiture is that it concentrates on goodness. It seeks to capture participants' view about what is important and good in their practice. This is significantly different from some other methodologies that highlight the need for improvement of educators' practice [4]. Social researchers tend to "focus their investigations on pathology and disease rather than on health and resilience” [8] (p. 8). However, in some situations, educators can gain more from understanding success than from understanding failure. Furthermore, seeking goodness doesn't mean ignoring challenges in the case. Weakness can be recognized in the process of capturing goodness. Portraiture is generous as well as critical, with a view to positive outcomes.

\subsection{Participants}

This study involves five educators from five long day care. Each participant:

- $\quad$ is a monolingual English speaker;

- has a vocational diploma or university degree in early childhood education;
- has experience working with Chinese children and families.

I distributed information about the study and participant selection criteria to the directors of long day care in Sydney suburbs where Chinese community are located. The directors, in turn, identified the potential participants. I visited each centre to meet with staff and explain the study, and then obtained their informed consent.

This paper is a part of a doctoral project investigating Chinese children's language experiences. Participants in the larger project include Chinese children, their parents and their educators. This paper focuses on educators' language practices and their interactions with the children. The information of the educators and the Chinese children is listed in Table 1. Pseudonyms are used throughout this paper.

Table 1. Background of educators and focus Chinese children

\begin{tabular}{lllll}
\hline Educators & $\begin{array}{l}\text { Qualificati } \\
\text { on }\end{array}$ & $\begin{array}{l}\text { Focus } \\
\text { children }\end{array}$ & Age & $\begin{array}{l}\text { Percenta } \\
\text { ge of } \\
\text { ELLs in } \\
\text { the class }\end{array}$ \\
\hline Anna & Bachelor & Elli & 3.9 & $42 \%$ \\
\hline Lindy & Diploma & Lucas & 4.5 & $10 \%$ \\
\hline Mary & Diploma & $\begin{array}{l}\text { Emma \& } \\
\text { Imogene } \\
\text { (Twins) }\end{array}$ & 3.7 & $33 \%$ \\
\hline Rae & Bachelor & Jacky & 4.8 & $75 \%$ \\
\hline Virginia & Bachelor & Riana & 4.9 & $30 \%$ \\
\hline
\end{tabular}

\subsection{Data Collection and Analysis}

Data for this study were collected through nonparticipant observation and semi-structured interviews. I visited each centre four times. I informed educators in advance before each visit and educators were prepared for it. During the visits, I observed the educator's interactions with the focus Chinese children as well as with other children. During the last visit to each centre, I used a video camera to record interactions between educators and focus Chinese children, including routines such as mealtimes, spontaneous interaction, and planned group and individual activities. The interview was undertaken on the third visit to each setting, allowing me to develop some relationship with the educators. During the interviews, the educators introduced their views on language development and education of ELLs based on their knowledge and understanding, and the strategies they used to support the focus children to develop their English skills. I found that educators did not just simply try to involve Chinese children in routines. They set the 
room, planned the programs, and organized the activities with their understanding of language education at the forefront. In addition to undertaking interviews, I had opportunities for additional conversation with the educators during each visit. These conversations, along with some activities that I observed but had not been filmed, were recorded in field notes. In these conversations, educators explained the ideas behind their practice or introduced other practices that they couldn't show me on the observation days. For example, after the "Shopping basket" game, Lindy explained that she had another way to play the game if she found that some children had difficulty repeating the sentence. She would say the sentence "I went to the shop and I bought...”, and let the children come to her, pick up the item and put it into the shopping basket. It is noticeable that no matter whether in formal conversations, in interviews or in casual conversations during my visits, educators tried to display the goodness of their practices.

After data collection, I started to craft the portraits. I first reviewed interview data, listing the strategies that educators introduced. I followed this by sieving the observation data and distilling strategies that were evident from both data sources. The careful refinement and filtering processes allowed me to summarize educators' practices and capturing the most salient characteristics of these.

In this process of developing individual portraits, the strategies identified that had been used by the educators were also analyzed with Cummins' framework of four types of language activities. The types of educators' strategies are in line with the characteristic of their portraits. I will discuss the types of the educators' activities after presenting the portraits.

\section{The portraits}

In this section, I will present the portraits of the five Australian educators' language practices. In each portrait, I will introduce the long day care centre as well as the educators' interactions with Chinese children based on their understanding regarding language education. First-person account is used in the description of the portraits that involve my voice and feelings.

\subsection{Lindy: Making Language Comprehensible by Building on Children's Previous Experiences}

Lindy is a very experienced educator who has worked in her preschool for over twenty years. She stated that the most attractive part of her preschool is its natural environment. Located in a quiet street next to a park, the preschool is surrounded by a big garden where staff and children may enjoy planting vegetables and flowers throughout the seasons. The low-level building stands beside the garden. A small lane starting from the veranda leads to the middle of the garden. Inside the building, a large space is divided into two parts by a sliding door. One part caters for the 3-4 year-old group and the other for 45 year-olds. Lindy works with the older age group. The majority of children in her group are AngloAustralian native English-speaking children. Two boys are from Chinese backgrounds. Lucas, the focus child, has been attending the preschool for about twelve months.

I observed that in the morning between 10 and 11 o'clock, the following scene takes place in Lindy's room. Lindy sits with Lucas and a few other children at the book corner, reading a book. This morning she read a book titled "The magic hat". She read through the book with a few stops, encouraging children to label some key words. For example, she asked "Can you please tell me ... the hat sits on the head of...?” "Giraffe!” a child answered. "Giraffe!” Lucas followed. Then she continued reading. When it was in afternoon group story time, Lindy took the book out again and read it to the group. All the children were attentive including Lucas, who showed interest by listening to it intently. After the reading, Lindy asked a girl to put the book in the room library where children can borrow books to take home and read them again. At the end of the day, Lucas' mum came to pick him up. Lindy reminded Lucas to borrow a book from the library to take home. He went to the shelf and picked up a book titled "Molly at the dentist" that was read a few days ago in the room.

As an educator with over thirty years' experience, Lindy showed comprehensive knowledge and skills in language education by using a number of strategies for ELLs’ English learning such as modeling with slow and clear language, using visual aids and involving parents. She highly values the strategy of creating opportunities for ELLs to comprehend language by building on their previous experiences through repetition. This is typically reflected in her book reading practices. Lindy states that pre-reading the story is necessary for ELLs to gain a good understanding in group reading activities.

"The other thing we do is read the book that we're having for group time. We'd read it to the children to prepare them for it, and go through and pick out key words and that sort of things, so they have an understanding when they sit on the mat with the class. They've already been prepared for the story otherwise it would be hard for them to sit for a long time listening to something they don't fully comprehend."

Routine time seems to be another important avenue for Lindy to assist ELLs to develop their understanding of English through repetition. She tends to use the same words when giving routine instructions. "I try to make my directions the same 
for a long time, and then I'll try and mix them up to make sure they're really listening" she says.

Repetition and pre-teaching that build on children's previous experiences assist Lucas and other ELLs to gain a better understanding of language in different contexts. As Lucas has been in this centre for almost one year and starts to talk more in English, Lindy tends to encourage Lucas to express his ideas verbally in English. For example, once Lucas showed her the castle made by him and his friend. Lindy encouraged him to describe which part he contributed to the castle. "What part did you do?" She asked. Lucas answered with hand gesture "This part and this part".

\subsection{Mary: Including children in group activities with body language and action games}

At about 9:30 am one winter morning, I walked into a centre located beside a busy road. A colorful glass door behind the gate marks the centre on the road. Behind the door, a corridor leads to three rooms for three different age groups. Each group has a separate backyard for outdoor play. Mary's room is in the middle and caters to 3-4 year-old children. I opened the door but found an empty and quiet room. Where were the educators and the children? While I was puzzling over this, a burst of laughter came from the backdoor. They were in the backyard!

Stepping into the backyard, I was excited by the active sight in front of me. Mary was leading her group doing exercises under the warm winter sunshine in the bright backyard. "Next, we do kangaroo jumps" she said happily and started to jump. All children followed her and jumped behind. Emma and Imogene, the focus children, ran and jumped with the group. They held hands together and giggled cheerfully. "All right, bend your knees. Emma, bend your knees”. Mary did the action while talking to her. Emma and Imogene then bend their knees by following her. All children laughed while doing the actions, their laughter covering the traffic sounds from outside the fence.

After the exercise, children had a free play in the backyard for about one hour before Mary gathered them again to sing action songs. Before lunch, Mary played a game of musical statues. Emma and Imogene actively participated in these activities. When they were confused by the instructions, Mary guided them with body language. For example, when Emma won the statue game at last, Mary said "Emma, come to get your prize.” But Emma walked away from her, Mary then used her hands to guide Emma taking a prize from a bag.

Mary is a vibrant educator who has four years experiences in early childhood education. She claimed that she doesn't have a lot of experience working with children who learn English as a second language. About one third of the children in her group are from non-English backgrounds. Mary tries to involve these children in group activities with action songs and games. She found ELLs, especially Emma and Imogene, enjoy these activities. Using body language and actions seem to be Mary's main strategies to help ELLs settle in the group and understand the new language. She tends to exaggerate her hand gestures in interactions with them. "I found I'll use my hands a lot. I do like, I tap my head and 'go to get your hat."

Her strategy is also reflected in her actions when teaching the concept of "Yes and No" to Emma and Imogene.

"And lately they are starting to learn 'yes' and 'no' [in English]. So I will be like, 'Oh, would you like more biscuit?' if they say no, I will put them away. And then they'll go 'yes', and then I will give it to them. So I'm trying to get them to learn the concept of 'yes' and 'no' now. So that's bit funny sometimes, 'cause' they looked at you like: why are you taking the biscuits away from me?"

\subsection{Rae: Making language meaningful with abundant visual aids}

Often in the morning, I see Rae standing at the door and greeting children when they walk into the room. What impressed me is that she greets Korean or Chinese children in their home language. These children answer her in English or their home language. The preschool at which Rae works is located in an area with fairly large Chinese and Korean communities. Over seventy percent of children in this preschool are from Chinese or Korean backgrounds. Rae showed interest in fostering these children's home language and she is learning Korean. This preschool has a big yard (close to a thousand square metres) for fifty children that are divided into two age groups: 3-4 years old, and 4-5 years old. Rae works with the older group.

When the day starts at about 9:30 am, Rae usually gathers the children in front of a felt board and discusses the weather, date, day and seasons while asking children to place accompanying pictures on the board. For example, when she talks about the season, she may ask who knows what season it is now. After the children say "winter", she will invite a child to come to the front and choose the picture of winter from a small basket and place it on the board. This activity is usually followed by another discussion about routines of the day, during which she displays the routines with pictures that are placed in another basket.

Walking into Rae's room, I noticed a range of different-sized baskets that are not only full of toys, but pictures. Rae has pictures everywhere! The contents of the pictures include the routine activities (e.g. wash hands, drink water), the items in the preschool (e.g. dust pan, painting easel), children's belongings (e.g. lunch box, hat), and the concepts 
that are always used for educational activities (e.g. colours and shapes). The pictures range in size from A4 to small pieces that are suitable to hang on key rings. Rae stated that the key rings pictures are popular with the children. She told me that Jacky, the focus child, showed a keen interest in them as he just started to use English to communicate with simple words. The key rings are convenient for him to carry around. When he has difficulty in expressing ideas properly, he can flip over the pictures hanging on the key ring and choose one that help express his ideas.

To Rae, visual aids play an important role in interaction with and education of ELLs. Visual aids help ELLs to understand the meaning of language in conversation. They are very handy in the preschool.

"They [visual cards] are all over the place and it is very important. I find in practice it is very powerful when the visual aids are in different sizes. So I have hundreds in the room. They are in different baskets."

This practice might be partly due to the high percentage of ELLs in the preschool. It is observed that pictures are used often by educators in routines, such as they show the picture of washing hands when asking children to do so. Pictures seem to be necessary for communication when the majority of the children have difficulties in understanding the educators' language.

Besides pictures, Rae frequently uses props in educational activities. She once read a book introducing Australian plants. After a few minutes, some children including Jacky were unsettled. Rae took out a basket that was full of different types of bark. Some pieces were introduced in the book. She displayed the pieces of bark and invited children to touch them and tell which is smooth and which is rough. Jacky was attracted by the pieces of bark and touched them a few times. They helped him understood more about the information presented in the book. He seemed to have more interest in the book afterwards and listened to the rest of the story sitting in a settled manner.

\subsection{Virginia: Fostering ELLs' confidence in using English through repeating and multicultural activities}

Virginia works at a long day care centre located in a suburb where the number of Asian residents has recently increased rapidly. According to Virginia, Asian children in this centre, mainly from Chinese and Korean backgrounds have increased from approximately five to about fifteen in a few years, accounting about thirty percent of children at the centre. She felt that there is a need for her to increase knowledge in the education of ELLs. The centre has two rooms. Blue room is for toddlers aged 2-3 years old. Red room caters for preschoolers aged above three. Virginia works in Red room.
Walking into Red room at the first time, I was drawn to a group of children dancing vigorously in front of a big TV screen rotating through pictures of landmarks of different countries. Riana, the focus child was dancing in the group too. However, she was soon attracted to the activity that Virginia was doing at a table. She went there and sat next to Virginia. "Riana, do you want to make a Chinese flag?” asked Virginia as she guided children to make some national flags. Riana nodded her head and looked at a piece of red paper near another child. "Do you want to ask Felix to give you the paper" Virginia asked. Riana nodded her head again. Virginia asked Felix "Can you please pass the paper to Riana?" Felix followed her instruction. Virginia then said to Riana "Say thank you to Felix." "Thank you" Riana said in a small voice.

Virginia noticed that many ELLs lack confidence in communicating with educators and peers. She showed concern about some perceived difficulties in her relationship with ELLs caused by language issues.

"But they don't understand what I am saying, so it is hard to communicate and it can be very scary for them. So they do not want to come to me at first because it's all about trust and I can understand how it could be very scary when you're not understanding."

She stated that making children comfortable and building up confidence is a central element in developing a new language and initially, bilingual staff (currently two full-time) play a critical role.

"So having Winnie (Chinese staff) and Kelly (Korean staff), it does help that initial period, just for them to find somebody that they feel comfortable with. They'll see their parents communicating with them, so they start to feel more comfortable. Then they are confident, because that is the main thing that many things can build on, the language and other areas."

In order to help ELLs develop confidence in using English, Virginia used the strategy of repeating stories and songs. For example, she may guide children to sing songs first in a small group and then give them opportunities to sing in the big group.

"We encourage children to take their turn to take a leadership role to sing for the group. It can start in [small] groups if they are not as confident. So they are becoming more familiar with the repetition, and then give their turn."

Multicultural activities such as making national flags are often seen in the centre. To Virginia, though multicultural activities are not directly connected to language education, they help develop ELLs' sense of belonging, in turn, increasing their confidence in communicating in the new language. Some language activities reflect her idea about foster children's sense of cultural identity. 
"We do that across the board. With songs, we learn different cultural songs, different languages... So that they are becoming more of the different cultures. That is within our centre and then the Chinese children themselves get a chance to feel a part of it."

\subsection{Anna: Including ELLs as one of the group}

Growing up in the country, Anna describes herself as an uncomplicated and positive person who has learnt a lot from her experiences in Sydney. Educating and caring for ELLs is one of the things that she is currently learning because of the wide diversity of children and families that she encounters in the city. She is a new room leader of the 3-4 years old in her centre. This centre is located within the campus of a large organization consisting of many buildings. Most parents of children at the centre are professionals from different cultural backgrounds. Up to forty percent of preschoolers in Anna's group are from non-English backgrounds.

Anna likes to set up big areas with a wide variety of props and furniture for children to play freely in small groups, interacting with one another in any language. Elli, the focus child who was quiet most time in the centre, usually spends a long time in home corner or dress up corner with her Chinese friends, playing make-believe games in Chinese. Anna occasionally joins their play. Once, when Elli and Samantha dressed up as princesses, Anna suggested how about putting a princess crown on as well. She used her hand gestures to show putting a crown on her head, then pointed to a box and suggested that the girls look for the crowns in there. Samantha quickly went and got a crown; Elli went there later but couldn't found one. Anna then pointed to another box and asked Elli to check there. Elli followed her instruction and found another crown. She went back to play with Samantha happily.

Anna uses a lot of body language in her interactions with Elli and with other children regardless their background. She stated that she didn't apply any specific strategies in the education of ELLs. Though she used hand gestures and props very often, it is not specifically for ELLs, but for all children.

"We have a number of those children [ELLs] come here. I suppose, we don't necessarily do anything extremely different...I will definitely use a lot of hands gestures, of course, you know visual things. Actually, I did it to other children too, because some even though they speak English, they still don't listen to you."

It seems that Anna's main strategy is to address ELLs' needs in inconspicuous ways during daily interactions. She wants ELLs to feel comfortable without singling them out from the group. When reading a story to the group, she doesn't insist that children sit on the mat and listen to the story to the end. She allows children to move away from the mat and engage in other quiet activities if they lose interest in the story. For example, once she read a book that lasted for around fifteen minutes. Elli and a few other children walked away about half way through the story and played puzzles on another mat. Anna observed that but she didn't say anything to them. She continued reading the whole story to the rest of the children. She explained to me afterwards that she doesn't want to force children to sit on the mat to listen to a story that they have difficulties in understanding. She said that she believes these children will finally be settled in group story time and that there is no need to push them.

\section{Discussion}

Educators play a critical role in shaping ELLs' language experiences through their educational strategies and daily interactions [3]. Educators' language practices have a significant effect on ELLs' language development [2]. The purpose of this study was to investigate how the five Australian educators support ELLs, specifically Chinese children, in daily practices. These portraits display the complex and varied strategies employed by the educators in their different settings.

The five educators' practices were all closely related to the context in which the educators and children were engaged. The concept of context is a core consideration in Cummins' second language acquisition framework. According to Cummins [2], contextual support is essential to young ELLs' language development because it provides clues for the meanings of language. As showed in Figure 1, Cummins categorizes the language activities into four categories: context-embedded and cognitively undemanding (A type), context-embedded and cognitively demanding (B type), context-reduced and cognitively undemanding ( $\mathrm{C}$ type), contextreduced and cognitively demanding (D type). B type of language activities is most effective for the support of second language acquisition.

All the five educators used many contextembedded and cognitively undemanding activities (A type) in their interactions with the focus children. Lindy and Virginia organized the most contextembedded and cognitively demanding activities (B type). Lindy's strategy of pre-teaching key words of stories helped Lucas and other ELLs to be prepared for the story, making the activity comprehensible and interesting to these children. She also encouraged ELLs to take books home and read them again with parents, through which their interests were extended and their knowledge was reinforced. This practice is very effective in enhancing ELLs' competency in listening and reading skills [3]. Though her initial intention was more focused on 
increasing ELLs' confidence, Virginia's strategy of repetition of stories and songs positively influences their language skills. Repetition not only increases ELLs' confidence, but connects with their previous experiences enabling the activities to be more comprehensible and appealing [11]. Rae valued visual aids in communication. There were two situations for the use of visual aids in her centre: daily conversation and group activities. When the visual aids were used in daily conversation, the conversation was supported by the context, but it was cognitively undemanding (A type). For instance, educators used a picture of washing hands to instruct the children. However, using visual aids in group discussion or story reading is more cognitively demanding (B type). For example, Rae used the basket of bark to assist Jacky and other ELLs to understand the book she was reading. Mary and Anna used a great deal of body language in conversation. Their language was easy for ELLs to understand because of their gestures. These language activities are of the context-embedded and cognitively undemanding type (A type). None of the educators implemented context-reduced and cognitively undemanding activities ( $\mathrm{C}$ type) in their practices. However, context-reduced and cognitively demanding activities (D type) were recognized in some educators' practices. This is obviously evidenced in Anna's story reading activity. The story she read with the group was too challenging for Elli and other ELLs, resulting in their loss of interest. Though these children had the freedom to do something else, they lost an opportunity to learn from the story.

While portraiture allowed me to uncover goodness in educator's practices, this process similarly identified challenges that the educators faced. Mary and Anna seemed to lack holistic approaches in their practices. They relied heavily on body language at the expense of other strategies when interacting with the focus children. Anna's statement of interacting with Chinese children and other ELLs in the same way as with other children in fact raises a concern. The gap between ELLs and other children in English development can be substantial, and it takes five to ten years for ELLs to catch up. ELLs need educators' support in this process with educators' "empowering" practices that highlight the connection of educational activities and ELLs' experiences [2]. Making no difference between ELLs and other children in the interactions and in educational activities may reduce the opportunities for ELLs to achieve as much as they could do.

It is noticeable that no matter what goodness or challenges are found in the portraits, these educators all seemed to wish to be supportive of the Chinese children and other ELLs. According to Cummins's framework, the social power outside the educational settings could influence educators' attitudes and practices. Australia is a multilingual country and the status of languages other than English has been gradually improved in society and in educational policies in recent decades. In recent years, there has been substantial reform of early childhood education in Australia where multicultural and multilingual backgrounds of children are highly valued. The national curriculum framework, the Early Years Learning Framework, emphasizes children's sense of belonging and their connectedness with their cultural and linguistic background. These factors may underpin educators' positive attitudes and practices in supporting ELLs. The challenges in these educators' practices seemed to be influenced by their knowledge and understanding about how to educate ELLs rather than by the social power outside the long day care. This finding indicates that it is essential for educators to maximize their awareness of different types of language activities and their implications for language development in order to provide optimal opportunities for ELLs.

Another finding from the portraits is that besides educators' knowledge and experiences, their practices relating to ELLs' language education seemed be affected by the proportion of ELLs in their rooms. For example, Rae used many visual aids in her preschool to assist communication. The observation data showed that this practice was necessary due to the high percentage of ELLs in the setting (see Table 1) who required assistance with communication between educators and children. Educators had to frequently use pictures to explain their instructions. Likewise, Lindy's strategy of prereading stories was based on her idea of language education as well as on her setting, where the number of ELLs is small. The environment allowed her to pre-read a book to a small group. However, the same strategy would be difficult for Rae to apply when the majority of children in her room were ELLs. Rae's strategy of using props for story reading seemed to be more appropriate for her group. Additional research could be undertaken to examine the exact nature of the influence of educational environments on educators' practices relating to ELLs.

\section{Conclusions}

From the portraits of this study, it is obvious that differences exist among the educators' understanding and their competence in supporting ELLs' language development. While all the educators held a positive attitude to assist ELLs, however, some were not fully aware of effective strategies that would better benefit ELLs. Providing information for educators to increase their knowledge and skills for supporting ELLs is necessary.

Australian educational settings are experiencing a rapid increase of ELLs due to the high level of 
immigration. Working with ELLs has become a common issue confronting many educators. The findings from this study help inform pre-service and in-service education programs in relation to the language education of ELLs in early childhood settings.

\section{Acknowledgement}

The author thanks the educators for their participation in the research and for sharing their time and ideas so generously.

\section{References}

[1] Australian Government Department of Immigration and Citizenship, More than 65 years of post-war migration, 2013, Retrieved 30th May 2014, from http://www.immi.gov.au/media/fact-sheets/04fifty.htm, (Access Date: 12 June 2016).

[2] Cummins, J, Language interactions in the classroom: from coercive to cllaborative relations of power. In C. Baker (Ed.), Bilingual education: An introductory reader (pp. 108-136). Clevedon: Multilingual Matters, 2007.

[3] Echevarria, J. M., M. J. Vogt, and D. J., Short, Making content comprehensible for English learners: The SIOP Model (2nd ed.). Boston: Pearson, 2004.

[4] E. Rocha-Schmid, "Participatory pedagogy for empowerment: A critical discourse analysis of teacherparents' interactions in a family literacy course in London”, International Journal of Lifelong Eudcation, 29(3), 2010, 343-358.

[5] F. W. English, “A critical appraisal of Sara LawrenceLightfoot's portraiture as a method of educational research”, Educational Researcher, 29(7), 2000, 21-26.

[6] Garcia, E. E., and E. G. Frede, (Eds.), Young English language learners : Current research and emerging directions for practice and policy. New York: Teachers College Press, 2010.

[7] J. Hu, J. Torr, and P. Whiteman, "Australian Chinese parents' language attitudes and practices relating to their children's bilingual development prior to school”, Journal of Early Childhood Research, 12(2), 2014, 139-153.

[8] Lawrence-Lightfoot, S., and J. Hoffmann Davis, The art and science of portraiture. San Francisco: JosseyBass, 1997.

[9] Merriam, S. B, Case study research in education: A qualitative Approach, San Francisco, Jossey-Bass, 1988.

[10] NSW Government of Euducation \& Communities, "Language background other than English" 2011, Retrieved 30th May 2014, from https://www.det.nsw. edu.au/media/downloads/about-us/statistics-andresearch/key-statistics-and-reports/lbote/lbote2011.pdf (Access Date: 12 June, 2017).
[11] Peregoy, S. F., and O. F. Boyle, Reading, writing \& learning in ESL: A resource book for K-12 teachers (3rd ed.). New York: Longman, 2001.

[12] Ross, M., Bilinguality and learning in the early years. In D. Manjula (Ed.), Bilinguality and literacy: Principle and practice (2nd ed., pp. 50-68). New York: Continuum. 2007.

[13] S. J. Shin, Teaching English language learners: Recommendations for early childhood educators. Dimensions of Early Childhood, 38(2), 2010, 13-20.

[14] Tabors, P. O., One child, two languages: a guide for early childhood educators of children learning English as a second language (2nd ed). Baltimore: Paul H. Brookes Publishing Co. ,2008. 